\title{
Systematic Review and Meta-analysis of Short- versus Long-Acting Granulocyte Colony-Stimulating Factors for Reduction of Chemotherapy-Induced Febrile Neutropenia
}

\author{
Paul Cornes · Pere Gascon · Stephen Chan · Khalid Hameed • \\ Catherine R. Mitchell • Polly Field · Mark Latymer · Luiz H. Arantes Jr.
}

Received: July 9, 2018 / Published online: October 8, 2018

(c) The Author(s) 2018, corrected publication October/2018
Enhanced digital features To view enhanced digital features for this article go to https://doi.org/10.6084/m9. figshare.7105239.

Electronic supplementary material The online version of this article (https://doi.org/10.1007/s12325018-0798-6) contains supplementary material, which is available to authorized users.

The original version of this article was revised due to retrospective Open Access order.

P. Cornes $(\bowtie)$

Comparative Outcomes Group, 9 Royal Victoria

Park, Bristol BS10 6TD, UK

e-mail: paul.cornes@yahoo.co.uk

P. Gascon

Department of Hematology-Oncology, Hospital

Clínic, University of Barcelona, C/Casanova 143,

08036 Barcelona, Spain

S. Chan

Nottingham University Hospitals, Hucknall Road,

Nottingham NG5 1PB, UK
Methods: Medline ${ }^{\circledR} /$ Medline in-process, Embase $^{\circledR}$, and the Cochrane Library were searched for studies published between January 2003 and June 2016. A hand-search of relevant conference proceedings was conducted for meetings held between 2012 and 2016. Eligible studies were restricted to those reporting a direct, head-to-head comparison of short- versus long-acting G-CSFs for reduction of chemotherapy-induced febrile neutropenia. Risk-of-bias assessments were performed for full publications only.

Results: The search strategy yielded 4044 articles for electronic screening. Thirty-six publications were evaluated for the meta-analysis: 11 of 12 RCTs and 2 of 24 non-RCTs administered doses of the short-acting G-CSF filgrastim for $\geq 7$ days. In RCT studies, there was no statistically significant difference in outcomes of interest between short- and long-acting G-CSFs. In non-RCTs, the overall risk was lower with

\section{K. Hameed}

Sheffield University, Weston Park Hospital,

Whitham Road, Sheffield S10 2SJ, UK

C. R. Mitchell · P. Field

PharmaGenesis Oxford Central, Chamberlain

House, 5 St Aldates Courtyard, Oxford OX1 1BN, UK

M. Latymer

Pfizer Ltd, Ramsgate Road, Sandwich CT13 9NJ, UK

L. H. Arantes Jr.

Pfizer Inc, 235 East 42nd Street, New York,

NY 10017, USA 
long-acting G-CSF than with short-acting G-CSF for incidence of febrile neutropenia [overall relative risk $(\mathrm{RR})=0.67, P=0.023]$, hospitalizations (overall $\mathrm{RR}=0.68, \quad P<0.05$ ), and chemotherapy dose delays (overall $\mathrm{RR}=0.68$, $P=0.020)$.

Conclusions: Overall, the weight of evidence from RCTs indicates little difference in efficacy between the short- and long-acting G-CSFs if dosed according to recommended guidelines. There is some evidence for greater efficacy for long-acting G-CSFs in non-RCTs, which may be a result of under-dosing of short-acting G-CSFs in general practice in real-world usage.

Funding: Hospira Inc, which was acquired by Pfizer Inc in September 2015, and Pfizer Inc.

Keywords: Chemotherapy; Chemotherapyinduced febrile neutropenia; Filgrastim; Granulocyte colony-stimulating factor; Neutropenia; Oncology

\section{INTRODUCTION}

Chemotherapy-induced neutropenia is one of the most frequent adverse events reported during cytotoxic chemotherapy treatment [1]. Neutropenia increases the risk of infection, often leading to febrile neutropenia (FN) [1]. In the United States, the annual incidence of FN was estimated at 91,560 cases in 2012 [2]. In the United Kingdom, the estimated annual incidence of FN in 2012 was 19.4 per 1000 oncology admissions [3]. Development of FN during chemotherapy may necessitate an interruption or cessation of treatment with chemotherapy or result in a dose reduction in subsequent treatment cycles, which can jeopardize treatment response and, ultimately, patient survival [1]. Furthermore, FN may lead to life-threatening adverse events such as neutropenic sepsis, a significant cause of mortality in patients with cancer and neutropenia [4]. The potential economic impact of $\mathrm{FN}$ is also significant. In the United States, mean costs of cancer-related neutropenia or FN hospitalizations were estimated at $\$ 18,880$ per first FN-related hospitalization across $2007-2010$ and $\$ 24,770$ per stay in 2012 [2, 4].
Prophylaxis using granulocyte colony-stimulating factors (G-CSFs) decreases the risk of FN, the severity and duration of neutropenia, and the number of chemotherapy dose reductions or delays [5]. Furthermore, G-CSF prophylaxis supports delivery of optimal chemotherapy and improves survival outcomes [6, 7]. Filgrastim was the first G-CSF to be approved for the reduction of $\mathrm{FN}$, and the effect of this shortacting G-CSF is dependent on the duration of treatment [8]. A 2014 study by Weycker et al. demonstrated that the risk for chemotherapyinduced neutropenic complications was substantially higher with 1-3 days [odds ratio 2.4 (95\% CI 1.6-3.4)] and 4-6 days [odds ratio 1.9 (95\% CI 1.3-2.8)] versus $\geq 7$ days of treatment with filgrastim prophylaxis [8]. Product labeling recommends filgrastim administration once daily for up to 2 weeks or until the absolute neutrophil count (ANC) has reached $10,000 / \mathrm{mm}^{3}$ following its chemotherapy-induced nadir [9]. However, most patients treated in clinical practice receive daily G-CSF prophylaxis for $\leq 7$ days and such treatment is associated with worse neutropenia-related clinical outcomes [10, 11]. A pegylated form of filgrastim (pegfilgrastim) is also available; it is administered once per 2- to 3-week chemotherapy cycle because of its longer halflife [12].

Observational studies evaluating neutropenia-related outcomes in patients receiving myelosuppressive chemotherapy suggest that pegfilgrastim is more effective than filgrastim $[10,13-23]$. Literature reviews that evaluated the efficacy of short- and long-acting G-CSFs have mainly focused on clinical trial data $[24,25]$. However, a recent review of real-world comparative effectiveness studies found that risks of FN and FN-related complications were generally lower for prophylaxis with pegfilgrastim than with short-acting G-CSFs [26]. Therefore, a systematic literature review (SLR) was performed to identify both randomized controlled trial (RCT) and non-RCT studies that reported the use of G-CSF for the reduction of FN following myelosuppression due to chemotherapy. 


\section{METHODS}

\section{Systematic Literature Review (SLR)}

Medline ${ }^{\circledR} /$ Medline in-process, Embase ${ }^{\circledR}$, and the Cochrane Library were searched using the OVIDSP interface to identify studies published between January 1, 2003, and August 11, 2015. Search strings consisted of text words and Medical Subject Headings terms for G-CSFs, drug names, neutropenia, and study design (Supplementary Appendix Tables S1 and S2). The search strategy was executed on August 11, 2015 , and refreshed on June 15, 2016, to capture recent full-text publications. Searches were designed to overlap by 3 months with the original search date of August 2015 to allow for indexing lag within the databases.

To capture the latest studies not yet published as full-text articles and/or supplemental results of previously published studies, a handsearch of relevant conference proceedings held between 2012 and 2015 (or the most recent 3 years available) was conducted on August 24, 2015 (Supplementary Appendix Table S3), and refreshed on June 23, 2016, to include conferences held between 2015 and 2016. Bibliographic reference lists of eligible SLRs and metaanalyses were also examined for relevant publications. The final search result from each database was limited to references published in the English language.

\section{Eligibility Criteria}

Publications involving studies of adults (aged $>18$ years) with non-myeloid malignancies receiving myelosuppressive anticancer drugs or adults with acute myeloid leukemia receiving induction or consolidation chemotherapy were included in the review. Publications of interest included primary/secondary G-CSF prophylaxis or treatment with lenograstim (Granocyte ${ }^{\circledR}$ ), filgrastim $\left(\right.$ Neupogen $^{\circledR}$, Zarzio $^{\circledR}$, Nivestim $^{\circledR}$, Ratiograstim $^{\circledR}$ ), pegylated filgrastim (pegfilgrastim, Neulasta ${ }^{\circledR}$ ), lipegfilgrastim (Longquex ${ }^{\circledR}$ ), Ro 25-8315, empegfilgrastim, maxy-G34, PEGrHuG-CSF, and BK0026. Eligible studies were further restricted to those reporting a direct, head-to-head comparison of short- versus longacting G-CSFs. Full details of the inclusion and exclusion criteria are provided in Supplementary Appendix Table S4. Outcomes of interest included the incidence of FN, neutropenia-related or all-cause hospitalizations, and chemotherapy dose reductions or delays due to neutropenia.

\section{Risk-of-Bias Assessment}

Two analysts screened the references in parallel, based on title and abstract. Risk of bias for full publications only was assessed by two independent reviewers; disputes were resolved by a third researcher. All publications that met the predefined inclusion/exclusion criteria for the review were obtained as full articles and reassessed against the review criteria. This process was fully compliant with the 2009 Preferred Reporting Items for Systematic Reviews and Meta-Analyses guidelines.

\section{Meta-analysis}

Results were analyzed by pair-wise meta-analysis. Results from relevant studies were entered into a $2 \times 2$ table and risk ratios were calculated. The Chi squared test of heterogeneity was used to test the assumption that the true effect did not differ between studies. If the Chi squared test gave a low $P$ value or a large Chi squared $\left(I^{2}\right)$ statistic relative to its degree of freedom and $I^{2}$ was high, there was evidence of heterogeneity and a random-effect meta-analysis was used. When heterogeneity was low, fixed-effect meta-analysis was used with Mantel-Haenszel methods.

It was originally agreed to exclude publications where the duration of administration of short-acting G-CSF was $<7$ days or those where the duration was not reported; however, among the non-RCTs identified, only two studies $[6,27-31]$ stated that treatment was given $\geq 7$ days, and therefore there were insufficient data to perform a sensitivity analysis that included only these studies. One non-RCT reported that long-acting G-CSF was given on the same day as chemotherapy [32]; this study 
was omitted from the meta-analysis. Among the RCTs, one study reported administration of the short-acting G-CSF for $<7$ days [33]. A sensitivity analysis for incidence of FN was performed by removing this study. All statistical analyses were performed using Stata (v.12).

\section{Compliance with Ethics Guidelines}

This article is based on previously conducted studies and does not contain any studies with human participants or animals performed by any of the authors.

\section{RESULTS}

\section{Literature and Conference Search}

The original search yielded 3970 articles, 3770 of which were excluded, resulting in 200 articles assessed for eligibility by full review (Supplementary Appendix Fig. 1i). Of these, 162 were excluded on full review and 6 additional publications were identified through supplemental searches. Therefore, a total of 44 references met criteria for inclusion [10, 13-23, 27, 29-59]. The refresher search yielded 530 articles, 514 of which were excluded, resulting in 16 articles assessed for eligibility by full review (Supplementary Appendix Fig. 1ii). Of these, 12 were excluded on full review, and no further relevant abstracts were identified through supplemental searches. Therefore, a total of four additional references met criteria for inclusion: two full publications from abstracts identified in the original screen $[6,28]$, one abstract containing further data from a previously identified abstract [60], and one poster containing data from a new study [61].

A detailed description of the studies can be found in Supplementary Appendix Tables S5 and S6. In total, 45 publications (17 RCTs; 28 non-RCTs) were included in the SLR [6, 10, 13-23, 27-61]. Of these, 36 (12 RCTs; 24 non-RCTs) were evaluated for the subsequent meta-analysis (Supplementary Appendix Table S7).

\section{RCTs}

Seventeen publications reported RCT data: five congress abstracts $[34,42,47-49,60]$, four full foreign language publications with an English abstract [52, 56, 58, 59], and eight full English language publications $[33,35,36,45,51$, $53,55,57]$. Publications reported data from RCTs conducted in China $(n=6)[51,52$, 56-59], multiple countries worldwide $(n=3)$ $[35,36,53]$, Russia $(n=2)[34,48,60]$, India $(n=2) \quad[47,49]$, Europe $(n=1) \quad[42]$, Korea $(n=1)$ [45], Italy $(n=1)$ [33], and the United States $(n=1)$ [55]. Studies compared pegfilgrastim with filgrastim $(n=10) \quad[33,35,36$, $42,45,49,51,53,55,57]$, the long-acting G-CSF empegfilgrastim with filgrastim $(n=2)$ $[34,48,60]$, and a pegylated G-CSF with an unpegylated daily dose G-CSF (drug name not provided; $n=5$ ) $[47,52,56,58,59]$.

\section{Non-RCTs}

Twenty-eight publications reported non-RCT data: 11 congress abstracts [14-17, 29, 31, 39-41, 43, 44], one congress poster presentation [61], and 16 full publications $[6,10$, $13,18-23,27,28,30,32,37,38,46,50,54]$. Publications reported non-RCT data from the United States $(n=10) \quad[10,15,16$, $18-20, \quad 22, \quad 30,38, \quad 46]$, Spain $(n=5)$ $[13,17,21,43,44]$, Canada $(n=3)[14,40,41]$, Germany $(n=3)[37,54,61]$, Greece $(n=2)$ $[23,32]$, multiple countries worldwide $(n=1)$ [39], Portugal $(n=1)[27,28]$, Singapore $(n=1)$ [29], Austria $(n=1)$ [50], and the United King$\operatorname{dom}(n=1)[6,31]$.

Twenty-two studies compared filgrastim with pegfilgrastim $[6,10,14-20$, $22,23,29-32,38-41,43,44,46,54]$; in one of these studies, the granulocyte-macrophage colony-stimulating factor sargramostim was administered as a concomitant therapy to both treatment arms [30]. Four studies compared filgrastim or lenograstim with pegfilgrastim $[13,21,50,61]$, and two studies compared a filgrastim biosimilar with filgrastim and pegfilgrastim [27, 28, 37]. 


\section{Incidence of FN}

\section{Evidence from RCTs}

Eleven RCTs assessed the incidence of FN with short- and long-acting G-CSFs (Supplementary Appendix Table S8) [33-36, 45, 48, 49, 51$53,57,60]$. Of these, nine studies included patients by specific cancer type [33-36, $45,48,49,53,57,60]$ and two included patients across cancer types [51, 52]. None of the RCTs reported a statistically significant difference in the incidence of FN between short- and longacting G-CSFs [33-36, 45, 48, 49, 51-53, 57, 60].

\section{Evidence from Non-RCTs}

Thirteen non-RCTs investigated the incidence of FN with short- and long-acting G-CSFs (Supplementary Appendix Table S8) $[10,13,14$, $18,21,23,27-29,32,38,41,50,54]$. Of these, 11 were retrospective cohort studies using data from an administrative claims database [13, 18], a pharmacy prescription database [29], patient medical records $[10,14,21,38,50]$, or records of patients who previously participated in prospective trials $[23,32]$, one reported a subanalysis of data from an RCT [54, 62], and one reported data from a single-center retrospective study that did not specify the data source $[27,28]$. One study was prospective and observational in design [41]. Studies assessed shortversus long-acting G-CSF prophylaxis in patients with breast cancer $(n=7)$ $[14,23,27,28,32,41,50,54]$, across cancer types $(n=5)[10,13,18,21,38]$, and in patients with lymphoma $(n=1)$ [29].

Six non-RCT publications reported no significant difference between short- and longacting G-CSFs $[23,27-29,38,41,50]$, five reported that pegfilgrastim was significantly superior to filgrastim $[10,13,14,18,54]$, one reported a numerical trend toward this result but did not perform a statistical analysis [21], and one reported that filgrastim was significantly more effective than pegfilgrastim [32].

\section{Meta-analysis: Short- versus Long-Acting $G$-CSFs on the Incidence of FN}

In the analysis of RCTs using a fixed-effect model (Fig. 1i), the overall risk for FN with long-acting
G-CSFs was generally lower than with short-acting G-CSFs [overall relative risk $(\mathrm{RR})=0.86$ ]; however, this difference was not statistically significant $(P=0.226)$. A sensitivity analysis, excluding one RCT wherein the duration of short-acting G-CSF administration was $<7$ days [33], confirmed the original analysis (overall RR $=0.87, P=0.261$ ). In the analysis of non-RCTs using a fixed-effect model (Fig. 1ii), the overall effect of long-acting G-CSF on FN was almost the same as that of short-acting G-CSF (overall RR $=0.98 ; P=0.681$ ). Using a random- rather than fixed-effect model (Supplementary Appendix Fig. 2), the overall risk for FN with long-acting G-CSF was generally lower than with short-acting G-CSF (overall $\mathrm{RR}=0.67$ ); this difference was statistically significant $(P=0.023)$.

\section{Incidence of Hospitalizations}

\section{Evidence from RCTs}

Five RCT publications reported hospitalization outcomes with short- versus long-acting G-CSF prophylaxis (Supplementary Appendix Table S9) [33, 35, 36, 49, 53]. Of these, three RCTs showed no significant difference between treatments [33, 36, 53], and two reported a trend toward fewer hospitalizations for pegfilgrastim versus filgrastim $[35,49]$.

\section{Evidence from Non-RCTs}

Fifteen non-RCT publications reported hospitalization outcomes with short- versus longacting G-CSF prophylaxis (Supplementary Appendix Table S9) $[13,15-22,27,28,30$, $43,44,54,61]$. Of these, nine reported that pegfilgrastim significantly reduced the incidence of hospitalization versus filgrastim $[13,15,16,18-20,22,54,61]$, two indicated a nonstatistical trend in this direction [17, 21], three reported no statistical difference between the two treatments [30,43,44], and one did not report a statistical analysis for this outcome $[27,28]$.

\section{Meta-Analysis: Short-versus Long-Acting $G$-CSFs on the Incidence of FN-Related Hospitalizations}

There were not enough RCTs reporting FNrelated hospitalizations to enable a meta- 
i

Author

Bozzoli et al., 2015

Filon et al., 2015; Nechaeva et al., 2015

Green et al., 2003

Grigg et al., 2003

Park et al., 2013

Salafet et al., 2013

Satheesh et al., 2009

Shi et al., 2013

Sierra et al., 2008

Zhang et al., 2015

Overall (original analysis) ${ }^{\mathrm{b}}$ Test of heterogeneity: $I^{2}=0.0 \% ; P=0.810$

Test of RR $=1: Z=1.21 ; P=0.226$

Overall (sensitivity analysis) ${ }^{c}$

Test of heterogeneity: $I^{2}=0.0 \% ; P=0.743$

Test of RR $=1: Z=1.12 ; P=0.261$

ii

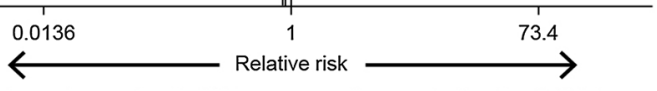

$\overbrace{\text { Favors long-acting G-CSF }}^{\longrightarrow}$

Author

Almenar Cubells et al., 2013

Almenar et al., 2009

Brito et al., 2012; 2016

Chan et al., 2011

Hershman et al., 2009

Kourlaba et al., 2015

Mates et al., 2012

Morrison et al., 2007

Schippinger et al., 2006

Tan et al., 2011

Von Minckwitz et al., 2008

Overall (fixed effect)

Test of heterogeneity: $I^{2}=80.0 \% ; P=0.000$

Test of RR $=1: Z=0.41 ; P=0.681$

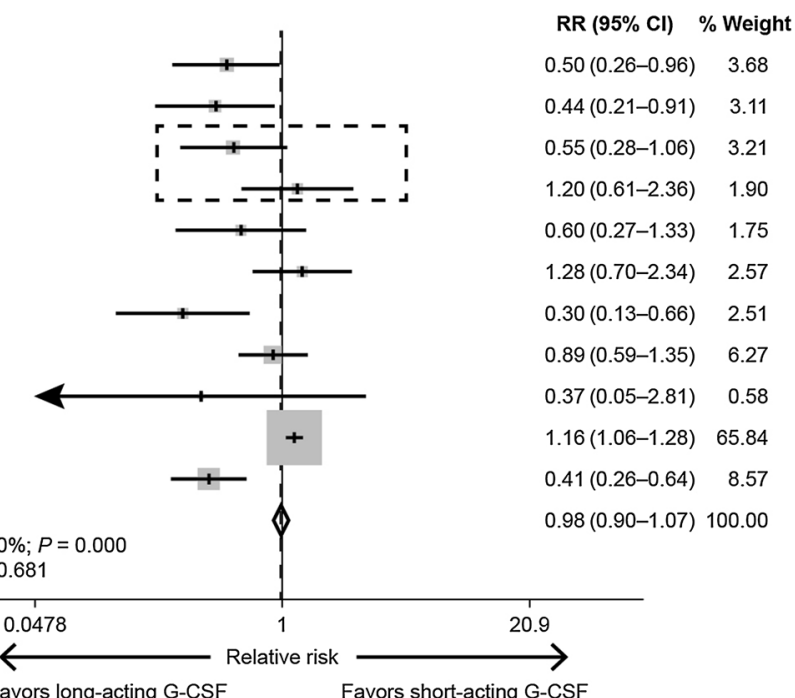

iii

Favors long-acting G-CSF

Favors short-acting G-CSF

Author

Almenar Cubells et al., 2013

Almenar et al., 2009

Brito et al., 2012; 2016

Heaney et al., 2009

Naeim et al., 2013

Tan et al., 2011

Von Minckwitz et al., 2008

Weycker et al., 2009 ${ }^{d}$

Weycker et al., 2012

Overall (fixed effect)

Test of heterogeneity: $I^{2}=64.8 \% ; P=0.004$

Test of RR = 1: $Z=3.77 ; P=0.000$
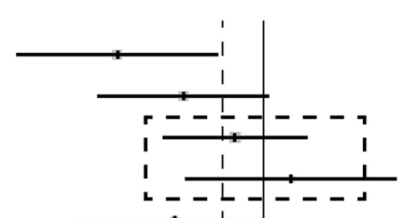

RR $(95 \% \mathrm{Cl}) \quad \%$ Weigh

$0.25(0.10-0.66) \quad 2.07$

$0.47(0.21-1.05) \quad 1.73$

$0.77(0.39-1.51) \quad 1.86$

$1.30(0.48-3.47) \quad 0.68$

$0.43(0.18-1.07) \quad 0.95$

$0.31(0.19-0.51) \quad 3.82$

$0.39(0.16-0.98) \quad 1.65$

$0.79(0.68-0.92) \quad 30.27$

$0.66(0.59-0.75) \quad 56.97$

$0.68(0.62-0.74) 100.00$

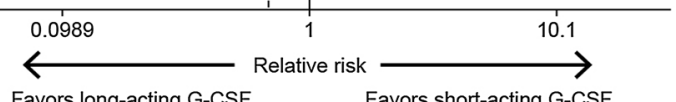

Favors long-acting G-CSF Favors short-acting G-CSF 
4Fig. 1 Meta-analysis to investigate the effect of shortversus long-acting G-CSFs on the incidence of FN in RCTs and non-RCTs and the incidence of FN-related hospitalizations in non-RCTs. ${ }^{\text {a }}$ i Meta-analysis of FN incidence in RCTs, ii meta-analysis of FN incidence in non-RCTs using a fixed-effect model, and iii meta-analysis of the incidence of FN-related hospitalizations in nonRCTs using a fixed-effect model. ${ }^{a}$ The dotted square shows studies in which G-CSF administration adhered to label recommendations ( $\geq 7$ days of treatment). ' Shi et al. [52] was excluded from the original analysis because no FN events were reported in either treatment group. ${ }^{c}$ Bozzoli et al. [33] was excluded from the sensitivity analysis because the duration of G-CSF administration was $<7$ days. "Results are based on a "broad" definition of FN, defined using hospital codes for neutropenia, fever, and infection. $C I$ confidence interval, $F N$ febrile neutropenia, $G$-CSF granulocyte colony-stimulating factor, $I^{2}$ Chi squared, $R C T$ randomized controlled trial, $R R$ relative risk

analysis to be performed. In the meta-analysis of non-RCTs using a fixed-effect model (Fig. 1iii), the overall risk of FN-related hospitalizations associated with long-acting G-CSF was generally lower than with short-acting G-CSF (overall RR $=0.68 ; P<0.05$ ).

\section{Chemotherapy Dose Reductions or Delays due to Neutropenia}

\section{Evidence from RCTs}

Four RCTs reported chemotherapy dose reductions and/or delays due to neutropenia; all studies reported similar levels of dose reduction or delay between short- and long-acting G-CSF (Supplementary Appendix Table S10) $[33,35,36,42]$.

\section{Evidence from Non-RCTs}

Ten non-RCTs reported chemotherapy dose reductions and/or delays due to neutropenia (Supplementary Appendix Table S10) $[6,13,17,21,23,27-29,31,32,41,54]$. Of these, two reported similar incidences of dose reduction between daily G-CSF and pegfilgrastim $[27,28,54]$, three reported no difference between treatments for this outcome or chemotherapy delays $[29,32,41]$, two reported a statistically significant result for higher incidence of dose reduction or delay with daily G-CSF versus pegfilgrastim [13, 23], and two reported a numerical trend toward this result $[17,21]$. The remaining non-RCT reported that $84.9 \%$ (pegfilgrastim) versus $69.5 \%$ (filgrastim) of patients achieved $\geq 85 \%$ relative dose intensity; authors did not state whether this was a significant result [31].

\section{Meta-analysis: Short- versus Long-Acting $G$-CSFs on the Incidence of Chemotherapy Dose Reductions and Delays}

There were not enough RCTs reporting chemotherapy dose reductions and delays to enable a meta-analysis. In the meta-analysis of non-RCTs using a fixed-effect model (Fig. 2), the overall risks of chemotherapy dose reductions (overall $\mathrm{RR}=0.69, P<0.05$ ) and delays (overall $\mathrm{RR}=0.70, P<0.05)$ with long-acting G-CSF were generally lower than with short-acting G-CSF. In the meta-analysis of non-RCTs using a random-effect model (Supplementary Appendix Fig. 3), the overall risk of chemotherapy delays with long-acting G-CSF was generally lower than with short-acting G-CSF (overall $\mathrm{RR}=0.68, P=0.020$ ).

\section{DISCUSSION}

This SLR identified RCTs and non-RCTs that reported head-to-head comparisons of shortversus long-acting G-CSFs for the reduction of chemotherapy-induced FN. When short-acting G-CSF was dosed according to treatment guidelines, there was no statistically significant difference in the incidence of $\mathrm{FN}$, hospitalizations, and chemotherapy dose reductions and/ or delays between short- and long-acting G-CSFs among RCT results. This is important because FN-related hospitalizations are common, distressing, and costly $[2,4]$. This analysis confirms the recommendations of the American Society of Clinical Oncology and the European Society of Clinical Oncology that indicate that either filgrastim or pegfilgrastim can be used for the prevention of treatment-related $\mathrm{FN}$, with the choice of agent dependent on convenience, cost, and clinical situation [63, 64]. 


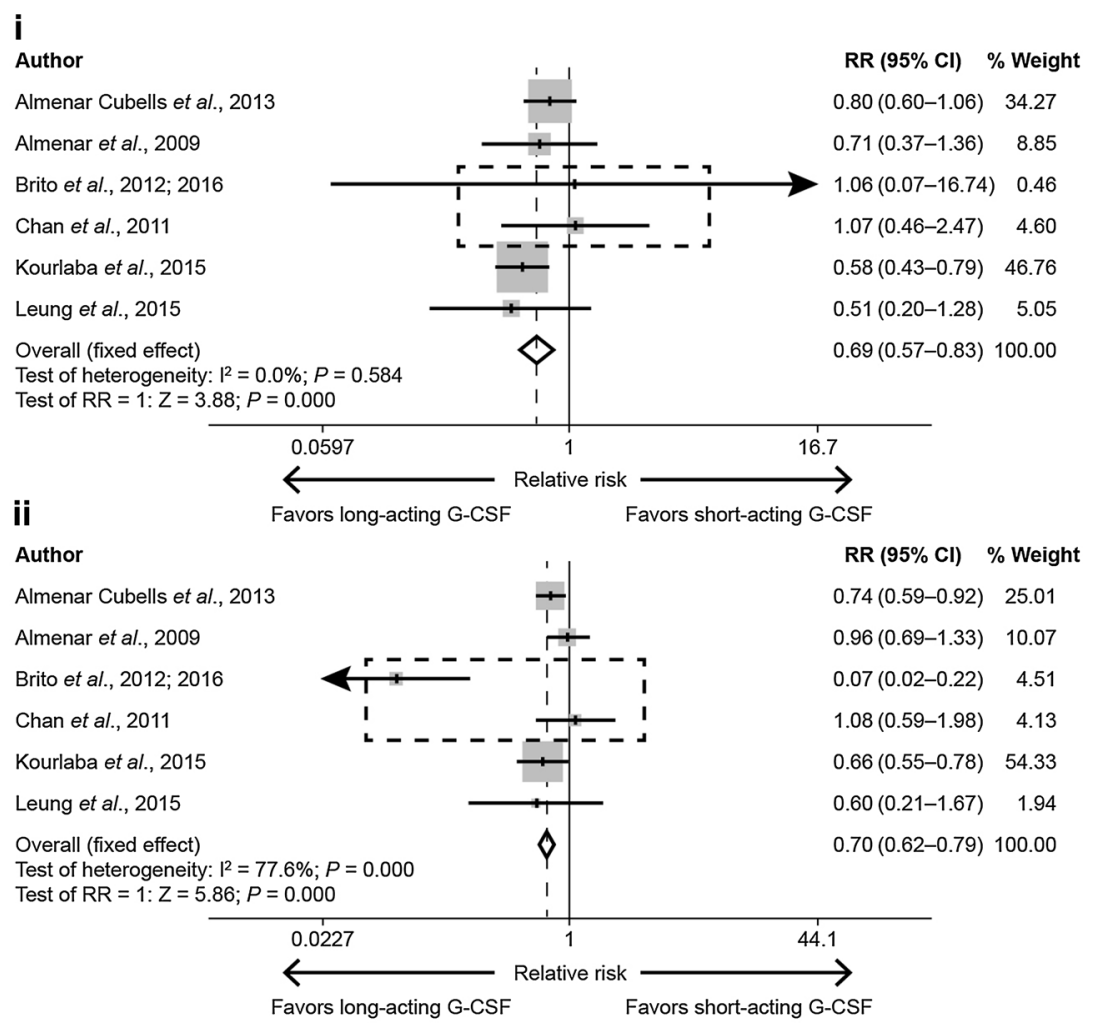

Fig. 2 Meta-analysis to investigate the effect of shortversus long-acting G-CSFs on the incidence of chemotherapy dose reductions and dose delays in non-RCTs. ${ }^{\mathrm{a}} \mathbf{i}$ Metaanalysis for chemotherapy dose reductions in non-RCTs using a fixed-effect model, and ii meta-analysis for chemotherapy dose delays in non-RCTs using a fixed-

The approved dosing schedule for shortacting G-CSF treatment is $5 \mu \mathrm{g} / \mathrm{kg}$ once daily, commencing $24 \mathrm{~h}$ after chemotherapy and continuing for up to 2 weeks or until the ANC has recovered $\left(10,000 / \mathrm{mm}^{3}\right)$ following its chemotherapy-induced nadir [9]. However, an analysis of administrative claims data demonstrated that almost half of filgrastim users received treatment for $\leq 6$ days [46]. Furthermore, an observational study reported lower adherence to treatment guidelines and recommendations for timing of G-CSF initiation with use of filgrastim/lenograstim versus pegfilgrastim [65]. Among the studies identified in this SLR, few non-RCTs (2 of 24) and nearly all RCTs (11 of 12) indicated that short-acting G-CSF was administered for $\geq 7$ days $[6,27-31,34-36,42$, $45,48,49,51-53,57,60]$. This observation effect model. ${ }^{\text {a }}$ The dotted square indicates studies in which G-CSF administration adhered to label recommendations ( $\geq 7$ days of treatment). CI confidence interval, G-CSF granulocyte colony-stimulating factor, $I^{2}$ Chi squared, $R C T$ randomized controlled trial, $R R$ relative risk

supports other evidence of under-dosing of short-acting G-CSFs in real-world clinical practice and that compliance is likely to be lower in routine clinical practice compared with RCTs. Furthermore, this may explain, in part, the difference between the results from the RCT and non-RCT studies in this analysis.

Most (11 of 17) RCTs included in this metaanalysis were described as open-label $[36,42,45,47,48,51,52,55,57-59]$. The absence of blinding in open-label studies may increase the risk of performance and detection bias. However, study design appeared to have minimal impact on the relative efficacy of short- versus long-acting G-CSFs; only 1 of 11 open-label studies reported a significant result across all outcomes of interest, with longer duration of grade $3+$ neutropenia reported for 
patients treated with short- versus long-acting G-CSF [57]. Furthermore, a risk of bias assessment (results not shown) indicated the majority of studies were of high quality, and most were published from 2010 onward. Substantial changes in clinical practice over this period were not likely, which may have impacted treatment response in patients.

Some inherent limitations of this type of review are acknowledged: some FN events may not have been captured accurately, differences in the algorithms used for FN make comparisons between studies difficult, and some studies may have been underpowered to detect any differences in FN and FN-related endpoints. It is also important to note that new studies may have been published since completion of the systematic review (June 2016). Additionally, for the evidence presented from retrospective studies (from sources such as claims databases and pharmacy prescription databases), the accuracy and completeness of the information is uncertain.

Overall, the weight of evidence indicates little difference in efficacy between the shortand long-acting drugs if the short-acting G-CSF is dosed according to recommended guidelines (RCT data) [33-36, 42, 45, 48, 49, 51-53, 57, 60]. There is some evidence for greater efficacy with long-acting G-CSFs in non-RCT studies $[10,13-23,54,61]$. However, this may be a result of under-dosing of short-acting G-CSFs in real-world general practice. If there is no clinical difference between short- and long-acting G-CSFs, then treatment choice could be based on differences in patient quality of life or economic factors. Patients may prefer long-acting G-CSF treatment because fewer injections are needed [66]. Currently, the cost of the longacting drug may outweigh any benefit of convenience. Filgrastim is less expensive than pegfilgrastim [30, 37, 67]. Nevertheless, use of fewer injections in routine practice than is recommended may be an attempt to limit treatment costs [24].

Biosimilars, biologic products that are highly similar to a licensed (i.e., reference or originator) biologic drug $[68,69]$, may provide a lowercost alternative to originator biologic therapies. Filgrastim biosimilars are available worldwide
[70]; the availability of short-acting G-CSF biosimilars might be a way to regulate cost while maintaining the recommended dosing schedule [24] to ensure improved health outcomes. A 2014 annual review issued by the Pharmaceutical Management Agency of New Zealand reported a significant reduction of costs in the total G-CSF market and a nearly 25\% expansion in G-CSF usage following introduction of biosimilar filgrastim in 2012 [71]. Better access to G-CSFs also had a significant public health impact; the incidence of FN in women receiving chemotherapy for breast cancer decreased from one-third to less than 7\% [71]. Biosimilars of pegfilgrastim are only just becoming available; the availability of longacting G-CSF biosimilars may improve access to treatments that are more convenient for patients while remaining cost-effective.

\section{ACKNOWLEDGEMENTS}

Funding. This systematic literature review and meta-analysis was funded by Hospira Inc, which was acquired by Pfizer Inc. in September 2015, and by Pfizer Inc. Article processing charges were funded by Pfizer Inc.

Medical Writing, Editorial, and Other Assistance. This systematic literature review and meta-analysis was developed by Catherine R. Mitchell and Polly Field. Medical writing and editorial support was provided by Merry $\mathrm{H}$. Saba, PharmD, and Elyse Smith, PhD, of Engage Scientific Solutions, and funded by Pfizer Inc.

Authorship. All authors had full access to all of the data in this study and take complete responsibility for the integrity of the data and accuracy of the data analysis. All named authors meet the International Committee of Medical Journal Editors (ICMJE) criteria for authorship for this article, take responsibility for the integrity of the work as a whole, and have given their approval for this version to be published. 
Disclosures. Paul Cornes has received honoraria from Accord Healthcare, Amgen, Hospira/Pfizer Inc, Medicines for Europe/European Generics Medecines Association, Roche, Sandoz, and Teva Pharmaceutical Industries Ltd. Pere Gascon has provided consultancy/advisory services (uncompensated) for Hospira. Steve Chan and Khalid Hameed have nothing to disclose. Polly Field is Communications Director at PharmaGenesis Oxford Central, which received compensation from Hospira/ Pfizer Inc for development of the systematic literature review and meta-analysis. Catherine R. Mitchell was a consultant for PharmaGenesis Oxford Central at the time of development of the systematic review and meta-analysis. Mark Latymer is a full-time employee of, and declares stock holdings and/or stock options from, Pfizer Inc. Luiz H. Arantes is a full-time employee of, and declares stock holdings and/or stock options from, Pfizer Inc.

Compliance with Ethics Guidelines. This article is based on previously conducted studies and does not contain any studies with human participants or animals performed by any of the authors.

Data Availability. All data generated or analyzed during this study are included in this published article/as supplementary information files.

Open Access. This article is distributed under the terms of the Creative Commons Attribution-NonCommercial 4.0 International License (http://creativecommons.org/licenses/ by-nc/4.0/), which permits any noncommercial use, distribution, and reproduction in any medium, provided you give appropriate credit to the original author(s) and the source, provide a link to the Creative Commons license, and indicate if changes were made.

\section{REFERENCES}

1. Crawford J, Dale DC, Lyman GH. Chemotherapyinduced neutropenia: risks, consequences, and new directions for its management. Cancer. 2004;100:228-37.

2. Tai E, Guy GP, Dunbar A, Richardson LC. Cost of cancer-related neutropenia or fever hospitalizations, United States, 2012. J Oncol Pract. 2017;13:e552-61.

3. Schelenz S, Giles D, Abdallah S. Epidemiology, management and economic impact of febrile neutropenia in oncology patients receiving routine care at a regional UK cancer centre. Ann Oncol. 2012;23:1889-93.

4. Dulisse B, Li X, Gayle JA, Barron RL, Ernst FR, Rothman KJ, et al. A retrospective study of the clinical and economic burden during hospitalizations among cancer patients with febrile neutropenia. J Med Econ. 2013;16:720-35.

5. Wingard JR, Elmongy M. Strategies for minimizing complications of neutropenia: prophylactic myeloid growth factors or antibiotics. Crit Rev Oncol Hematol. 2009;72:144-54.

6. Leonard RC, Mansi JL, Keerie C, Yellowlees A, Crawford S, Benstead $\mathrm{K}$, et al. A randomised trial of secondary prophylaxis using granulocyte colonystimulating factor ('SPROG' trial) for maintaining dose intensity of standard adjuvant chemotherapy for breast cancer by the Anglo-Celtic Cooperative Group and NCRN. Ann Oncol. 2015;26:2437-41.

7. Lyman GH, Dale DC, Culakova E, Poniewierski MS, Wolff DA, Kuderer NM, et al. The impact of the granulocyte colony-stimulating factor on chemotherapy dose intensity and cancer survival: a systematic review and meta-analysis of randomized controlled trials. Ann Oncol. 2013;24:2475-84.

8. Weycker D, Barron R, Edelsberg J, Kartashov A, Legg J, Glass AG. Risk and consequences of chemotherapy-induced neutropenic complications in patients receiving daily filgrastim: the importance of duration of prophylaxis. BMC Health Serv Res. 2014;14:189.

9. Amgen Inc. Neupogen (filgrastim) US prescribing information; 2018. http://pi.amgen.com/ /media/ amgen/repositorysites/pi-amgen-com/neupogen/ neupogen_pi_hcp_english.ashx. Last accessed 8 Aug 2018.

10. Morrison VA, Wong M, Hershman D, Campos LT, Ding B, Malin J. Observational study of the prevalence of febrile neutropenia in patients who received filgrastim or pegfilgrastim associated with 3-4 week chemotherapy regimens in community oncology practices. J Manag Care Pharm. 2007;13:337-48. 
11. Weycker D, Hackett J, Edelsberg JS, Oster G, Glass AG. Are shorter courses of filgrastim prophylaxis associated with increased risk of hospitalization? Ann Pharmacother. 2006;40:402-7.

12. Amgen Inc. Neulasta (pegfilgrastim) US prescribing information; 2018. http://pi.amgen.com/ /media/ amgen/repositorysites/pi-amgen-com/neulasta/ neulasta_pi_hcp_english.pdf. Last accessed 8 Aug 2018.

13. Almenar Cubells D, Bosch Roig C, Jimenez Orozco E, Alvarez R, Cuervo JM, Diaz Fernandez N, et al. Effectiveness of daily versus non-daily granulocyte colony-stimulating factors in patients with solid tumours undergoing chemotherapy: a multivariate analysis of data from current practice. Eur J Cancer Care (Engl). 2013;22:400-12.

14. Mates MM, Hopman W, Altwairgi AK. Review of practice patterns of primary granulocyte-colony stimulating factor prophylaxis and impact on febrile neutropenia rate and chemotherapy delivery in patients with early breast cancer treated with modern adjuvant chemotherapy. J Clin Oncol. 2012;30:e19541.

15. Naeim A, Henk HJ, Becker L, Chia V, Badre S, Deeter RG. Pegfilgrastim use associated with lower risk of hospitalization than filgrastim use: a retrospective US claims analysis. Blood. 2010;116:3801.

16. Naeim A, Henk HJ, Becker L, Chia V, Badre S, Li X, et al. Pegfilgrastim prophylaxis is associated with a lower risk of hospitalization of cancer patients than filgrastim prophylaxis: a retrospective United States claims analysis of granulocyte colony-stimulating factors (G-CSF). BMC Cancer. 2013;13:11.

17. Salar A, Lopez A, Pio Torres J, Lopez MD, Caballero $\mathrm{MD}$, Prieto E, et al. Incidence of chemotherapy-induced neutropenia in lymphoma patients and use of prophylaxis with granulocyte colony-stimulating factors in clinical practice. Haematologica. 2009;94:521.

18. Tan H, Tomic K, Hurley D, Daniel G, Barron R, Malin J. Comparative effectiveness of colony-stimulating factors for febrile neutropenia: a retrospective study. Curr Med Res Opin. 2011;27:79-86.

19. Weycker D, Barron RL, Kartashov A, Oster G. Comparative effectiveness of pegfilgrastim, filgrastim, and sargramostim as prophylaxis against hospitalization for febrile neutropenia in cancer chemotherapy patients. J Manag Care Pharm. 2009;15:576-7.

20. Weycker D, Malin J, Barron R, Edelsberg J, Kartashov A, Oster G. Comparative effectiveness of filgrastim, pegfilgrastim, and sargramostim as prophylaxis against hospitalization for neutropenic complications in patients with cancer receiving chemotherapy. Am J Clin Oncol. 2012;35:267-74.

21. Almenar D, Mayans J, Juan O, Bueno JM, Lopez JI, Frau A, et al. Pegfilgrastim and daily granulocyte colony-stimulating factor: patterns of use and neutropenia-related outcomes in cancer patients in Spain-results of the LEARN Study. Eur J Cancer Care (Engl). 2009;18:280-6.

22. Henk HJ, Becker L, Tan H, Yu J, Kavati A, Naeim A, et al. Comparative effectiveness of pegfilgrastim, filgrastim, and sargramostim prophylaxis for neutropenia-related hospitalization: two US retrospective claims analyses. J Med Econ. 2013;16:160-8.

23. Kourlaba G, Dimopoulos MA, Pectasides D, Skarlos DV, Gogas H, Pentheroudakis G, et al. Comparison of filgrastim and pegfilgrastim to prevent neutropenia and maintain dose intensity of adjuvant chemotherapy in patients with breast cancer. Support Care Cancer. 2015;23:2045-51.

24. Klastersky J, Awada A. Prevention of febrile neutropenia in chemotherapy-treated cancer patients: pegylated versus standard myeloid colony stimulating factors. Do we have a choice? Crit Rev Oncol Hematol. 2011;78:17-23.

25. Wang L, Baser O, Kutikova L, Page JH, Barron R. The impact of primary prophylaxis with granulocyte colony-stimulating factors on febrile neutropenia during chemotherapy: a systematic review and meta-analysis of randomized controlled trials. Support Care Cancer. 2015;23:3131-40.

26. Mitchell S, Li X, Woods M, Garcia J, Hebard-Massey $\mathrm{K}$, Barron R, et al. Comparative effectiveness of granulocyte colony-stimulating factors to prevent febrile neutropenia and related complications in cancer patients in clinical practice: a systematic review. J Oncol Pharm Pract. 2016;22:702-16.

27. Brito $M$, Esteves $S$, Andre R, Isidoro $M$, Moreira A. Abstract P1-15-03. Comparison of efficacy of primary prophylaxis with pegfilgrastim, filgrastrim and a biosimilar filgrastim in TAC regimen (docetaxel, doxorubicin and cyclophosphamide). Cancer Res. 2012;72:P1-15-03.

28. Brito M, Esteves S, Andre R, Isidoro M, Moreira A. Comparison of effectiveness of biosimilar filgrastim (Nivestim), reference Amgen filgrastim and pegfilgrastim in febrile neutropenia primary prevention in breast cancer patients treated with neo(adjuvant) TAC: a non-interventional cohort study. Support Care Cancer. 2016;24:597-603.

29. Chan A, Leng XZ, Chiang JY, Tao M, Quek R, Tay K, et al. Comparison of daily filgrastim and pegfilgrastim to prevent febrile neutropenia in Asian 
lymphoma patients. Asia Pac J Clin Oncol. 2011;7:75-81.

30. Heaney ML, Toy EL, Vekeman F, Laliberte F, Dority BL, Perlman D, et al. Comparison of hospitalization risk and associated costs among patients receiving sargramostim, filgrastim, and pegfilgrastim for chemotherapy-induced neutropenia. Cancer. 2009;115:4839-48.

31. Leonard RCF, Mansi J, Benstead K, Stewart G, Yellowlees A, Adamson D, et al. 5033 Secondary PROphylaxis with G-CSF has a major effect on delivered dose intensity: the results of the UK NCRI/Anglo Celtic SPROG trial for adjuvant chemotherapy of breast cancer. EJC Suppl. 2009;7:271.

32. Skarlos DV, Timotheadou E, Galani E, Samantas E, Grimani I, Lianos E, et al. Pegfilgrastim administered on the same day with dose-dense adjuvant chemotherapy for breast cancer is associated with a higher incidence of febrile neutropenia as compared to conventional growth factor support: matched case-control study of the Hellenic Cooperative Oncology Group. Oncology. 2009;77:107-12.

33. Bozzoli V, Tisi MC, Maiolo E, Alma E, Bellesi S, D'Alo F, et al. Four doses of unpegylated versus one dose of pegylated filgrastim as supportive therapy in R-CHOP-14 for elderly patients with diffuse large B-cell lymphoma. Br J Haematol. 2015;169:787-94.

34. Filon O, Nechaeva M, Burdaeva O, Vladimirov VI, Lifirenko I, Kovalenko NV, et al. Efficacy and safety of empegfilgrastim, a novel pegylated G-CSF: results of complete analysis after 4 cycles of myelosuppressive chemotherapy in phase III double-dummy randomized clinical study. J Clin Oncol. 2015;33:e20735.

35. Green MD, Koelbl H, Baselga J, Galid A, Guillem V, Gascon P, et al. A randomized double-blind multicenter phase III study of fixed-dose single-administration pegfilgrastim versus daily filgrastim in patients receiving myelosuppressive chemotherapy. Ann Oncol. 2003;14:29-35.

36. Grigg A, Solal-Celigny $\mathrm{P}$, Hoskin $\mathrm{P}$, Taylor $\mathrm{K}$, McMillan A, Forstpointner R, et al. Open-label, randomized study of pegfilgrastim vs daily filgrastim as an adjunct to chemotherapy in elderly patients with non-Hodgkin's lymphoma. Leuk Lymphoma. 2003;44:1503-8.

37. Hadji P, Kostev K, Schroder-Bernhardi D, Ziller V. Cost comparison of outpatient treatment with granulocyte colony-stimulating factors (G-CSF) in Germany. Int J Clin Pharmacol Ther. 2012;50:281-9.

38. Hershman D, Hurley D, Wong M, Morrison VA, Malin JL. Impact of primary prophylaxis on febrile neutropenia within community practices in the US. J Med Econ. 2009;12:203-10.

39. Kubista E, Glaspy J, Holmes FA, Green MD, Hackett J, Neumann T, et al. Bone pain associated with once-per-cycle pegfilgrastim is similar to daily filgrastim in patients with breast cancer. Clin Breast Cancer. 2003;3:391-8.

40. Leung M, Eustaquio J, Kano J, Marr T, Higgins BP, Myers RE, et al. Pain severity and impairment of activity between pegfilgrastim (P) and fixed-dose filgrastim (F) in women with early-stage breast cancer receiving chemotherapy. J Clin Oncol. 2012;30:e19570.

41. Leung M, Florendo J, Kano J, Marr-Del Monte T, Higgins B, Myers R, et al. A modified filgrastim regimen does not reduce pain burden compared to pegfilgrastim in women receiving chemotherapy for non-metastatic breast cancer. Support Care Cancer. 2015;23:1669-77.

42. Lopez A, de Sevilla AF, Castaigne S, Greil R, Sierra J, Sanchez J, et al. Pegfilgrastim supports delivery of CHO-R chemotherapy administered every 14 days: a randomized phase II study. J Support Oncol. 2005;3:46-7.

43. Marina J, Carabantes FJ, Escrivá de Romani S, Pernas S, Cantos B, Carañana V, et al. 3019 Current practice of prophylaxis with granulocyte colonystimulating factors for preventing chemotherapyinduced neutropenia in breast cancer patients in Spain. Eur J Cancer Suppl. 2009;7:181.

44. Mazo EM, Gil-Fernandez JJ, Garcia Suarez J, Callejas Charavia M, Guerrero YM, Pascual Garcia T, et al. Comparative effect of filgrastim vs pegfilgrastim after chemotherapy on high grade non hodgkin lymphoma. Haematologica. 2009;94:231.

45. Park KH, Sohn JH, Lee S, Park JH, Kang SY, Kim HY, et al. A randomized, multi-center, open-label, phase II study of once-per-cycle DA-3031, a biosimilar pegylated G-CSF, compared with daily filgrastim in patients receiving TAC chemotherapy for earlystage breast cancer. Investig New Drugs. 2013;31:1300-6.

46. Phillips J, Ritter S, Starner CI, Gleason PP. Filgrastim (Neupogen) and pegfilgrastim (Neulasta): cost analysis and utilization management opportunity assessment. J Manag Care Pharm. 2012;18:176-7.

47. Ramkumar A, Nimmagadda R, Nirni SS, Aidris T, Anand A. A randomized, multi centre, open-label study to evaluate the efficacy and safety of Peg G-CSF as compared to grafeel in the prophylaxis of severe neutropenia in cancer patients receiving cytotoxic chemotherapy. Indian J Hematol Blood Transfus. 2013;29:388. 
48. Salafet OV, Chernovskaya TV, Sheveleva LP, Khorinko AV, Prokopenko TI, Nechaeva MP, et al. Efficacy and safety of BCD-017, a novel pegylated filgrastim: results of open-label controlled phase II study in patients with breast cancer receiving myelosuppressive chemotherapy. J Clin Oncol. 2013;31:e20593.

49. Satheesh CT, Tejinder S, Ankit J, Sajeevan KV, Lakshmaiah KC, Lokanatha D, et al. To analyze efficacy and safety of pegfilgrastim versus filgrastim in patients with breast cancer. J Clin Oncol. 2009;27:e20587.

50. Schippinger W, Holub R, Dandachi N, Bauernhofer $T$, Samonigg H. Frequency of febrile neutropenia in breast cancer patients receiving epirubicin and docetaxel/paclitaxel with colony-stimulating growth factors: a comparison of filgrastim or lenograstim with pegfilgrastim. Oncology. 2006;70:290-3.

51. Shi YK, Chen Q, Zhu YZ, He XH, Wang HQ, Jiang $\mathrm{ZF}$, et al. Pegylated filgrastim is comparable with filgrastim as support for commonly used chemotherapy regimens: a multicenter, randomized, crossover phase 3 study. Anticancer Drugs. 2013;24:641-7.

52. Shi YK, He XH, Yang S, Wang HQ, Jiang ZF, Zhu YZ, et al. Treatment of chemotherapy-induced neutropenia pegylated recombinant human granulocyte colony-stimulating factor: a multi-center randomized controlled phase II clinical study. Zhonghua Yi Xue Za Zhi. 2006;86:3414-9.

53. Sierra J, Szer J, Kassis J, Herrmann R, Lazzarino M, Thomas $X$, et al. A single dose of pegfilgrastim compared with daily filgrastim for supporting neutrophil recovery in patients treated for low-to-intermediate risk acute myeloid leukemia: results from a randomized, double-blind, phase 2 trial. BMC Cancer. 2008;8:195.

54. von Minckwitz G, Kummel S, du Bois A, Eiermann W, Eidtmann $H$, Gerber B, et al. Pegfilgrastim +/- ciprofloxacin for primary prophylaxis with TAC (docetaxel/doxorubicin/cyclophosphamide) chemotherapy for breast cancer. Results from the GEPARTRIO study. Ann Oncol. 2008;19:292-8.

55. Vose JM, Crump M, Lazarus H, Emmanouilides C, Schenkein D, Moore J, et al. Randomized, multicenter, open-label study of pegfilgrastim compared with daily filgrastim after chemotherapy for lymphoma. J Clin Oncol. 2003;21:514-9.

56. Zhang M, Lan HT, Chen L. Clinical observation of pegylated recombinant human granulocyte colonystimulating factor in preventing chemotherapy-induced neutropenia [Chinese]. Chin J New Drugs. 2014;23:815-8.
57. Zhang W, Jiang Z, Wang L, Li C, Xia J. An openlabel, randomized, multicenter dose-finding study of once-per-cycle pegfilgrastim versus daily filgrastim in Chinese breast cancer patients receiving TAC chemotherapy. Med Oncol. 2015;32:147.

58. Zhou S, Wang H, Zhang H, Qiu L, Qian Z, Li W, et al. A randomized controlled clinical study of pegylated recombinant human granulocyte colonystimulating factor in chemotherapy-induced neutropenia. Chin J Clin Oncol. 2011;38:1154-8.

59. Zhou SY, Shi YK, Gui L, Han XH, Wang L, Zhang CL. A randomized, open-label, single-dose, selfcontrolled, dose-escalation phase I study of Y-pegylated recombinant human granulocyte-colony stimulating factor. Chin J New Drugs. 2013;22:928-36.

60. Nechaeva MN, Burdaeva ON, Vladimirov VI, Lifirenko ID, Kovalenko NV, Kopp MV, et al. Efficacy and safety of empegfilgrastim, a novel pegylated G-CSF: results of double-dummy phase III study in patients receiving myelosuppressive chemotherapy. Support Care Cancer. 2015;23:S163-4.

61. Wetten S, Li X, Haas J, Worth G, Jacob C, Braun S, et al. Comparative effectiveness of granulocyte colony-stimulating factors (G-CSF) for reducing incidence of febrile neutropenia (Fn)-related hospitalization: a retrospective cohort study using German claims data. Value Health. 2015;18:A434.

62. von Minckwitz G, Kummel S, Vogel P, Hanusch C, Eidtmann H, Hilfrich J, et al. Intensified neoadjuvant chemotherapy in early-responding breast cancer: phase III randomized GeparTrio study. J Natl Cancer Inst. 2008;100:552-62.

63. Klastersky J, de Naurois J, Rolston K, Rapoport B, Maschmeyer G, Aapro M, et al. Management of febrile neutropaenia: ESMO Clinical Practice Guidelines. Ann Oncol. 2016;27:v111-8.

64. Smith TJ, Bohlke K, Lyman GH, Carson KR, Crawford J, Cross SJ, et al. Recommendations for the use of WBC growth factors: American Society of Clinical Oncology Clinical Practice Guideline Update. J Clin Oncol. 2015;33:3199-212.

65. Fagnani D, Isa L, Verga MF, Nova P, Casartelli C, Filipazzi $\mathrm{V}$, et al. Granulocyte colony-stimulating factors used in clinical practice: PoloNord Registry-Based Cohort Italian Study. Tumori. 2014;100:491-8.

66. Johnson P, Bancroft T, Barron R, Legg J, Li X, Watson $\mathrm{H}$, et al. Discrete choice experiment to estimate breast cancer patients' preferences and willingness to pay for prophylactic granulocyte colony-stimulating factors. Value Health. 2014;17:380-9. 
67. James E, Trautman H, Szabo E, Tang B, editors. Budget impact analysis of switching chemotherapy patients using granulocyte colony-stimulating factors (G-CSFs) from pegfilgrastim to short-acting G-CSFs in the United States (abstr 4668). Atlanta: American Society of Hematology; 2017.

68. Committee for Medicinal Products for Human Use (CHMP). Guideline on similar biological medicinal products; 2014. http://www.ema.europa.eu/docs/ en_GB/document_library/Scientific_guideline/2014/ 10/WC500176768.pdf. Last accessed 27 June 2017.

69. US Food and Drug Administration. Scientific considerations in demonstrating biosimilarity to a reference product: guidance for industry; 2015. http:// www.fda.gov/downloads/Drugs/GuidanceCompliance RegulatoryInformation/Guidances/UCM291128.pdf. Last accessed 27 June 2017.

70. Generics and Biosimilars Initiative (GaBi). Biosimilars of filgrastim [online posting]; 2015. http://www. gabionline.net/Biosimilars/General/Biosimilars-offilgrastim. Last accessed 27 Nov 2017.

71. PHARMAC Pharmaceutical Management Agency. PHARMAC Annual Review 2014; 2014. https:// www.pharmac.govt.nz/assets/annual-review-2014. pdf. Last accessed 28 Sept 2017. 